\title{
Self-inflating bag or Mapleson C breathing system for emergency pre-oxygenation?
}

\author{
R A Stafford, ${ }^{1}$ J R Benger, ${ }^{1}$ J Nolan²
}

\begin{abstract}
${ }^{1}$ Emergency Department, Bristol Royal Infirmary, Bristol, UK;

${ }^{2}$ Anaesthesia and Critical Care Medicine, Royal United Hospital Bath, UK
\end{abstract}

Correspondence to: Dr R Stafford, Accident \& Emergency Department, New Cross Hospital. Wolverhampton WV10 00P, UK; robstafford@ doctors.org.uk

Accepted 6 October 2007

\section{ABSTRACT}

Background: A crossover study was performed in healthy volunteers to compare the efficacy of a selfinflating bag with the Mapleson C breathing system for pre-oxygenation.

Method: 20 subjects breathed 100\% oxygen for 3 min using each device, with a 30 min washout period. The end tidal oxygen concentration and subjective ease of breathing were compared.

Results: There was a statistically significant difference in performance between the two devices, with the Mapleson C providing higher end expiratory oxygen concentrations at $3 \mathrm{~min}$. The mean (SD) end expiratory oxygen concentration was 74.2 (3.8)\% for the selfinflating bag $(95 \% \mathrm{Cl} 72.4 \%$ to $75.9 \%)$ and $86.2(3.7) \%$ for the Mapleson C system (95\% Cl 84.5 to 88.0);

$p<0.0001$. The $95 \% \mathrm{Cl}$ of the difference between the mean values for end expiratory oxygen concentration at 3 min was $10.0 \%$ to $14.2 \%$. There was also a statistically significant difference in the subjective ease of breathing, favouring the Mapleson C system.

Conclusion: The Mapleson C breathing system is more effective and subjectively easier to breathe through than a self-inflating bag when used for pre-oxygenation.

However, these benefits must be weighed against the increased level of skill required and possible complications when using a Mapleson C breathing system.

Pre-oxygenation is an established prerequisite to rapid sequence induction of anaesthesia and tracheal intubation. ${ }^{1}$ It is undertaken to maximise the oxygen fraction of the functional residual capacity by displacing nitrogen with oxygen. This delays the onset of oxygen desaturation of arterial blood after induction of apnoea. Good pre-oxygenation is essential in the emergency department before rapid sequence induction of anaesthesia, because intubation is often undertaken in patients with significant acute morbidity who are therefore prone to early and rapid desaturation. ${ }^{2}{ }^{3}$ Preoxygenation must therefore be optimal in this environment ${ }^{4}$ and emphasised during training. ${ }^{5}$ Adequate pre-oxygenation is indicated by achieving an end expiratory oxygen concentration of $>90 \% .^{67}$

Pre-oxygenation in the emergency department is often achieved using a self-inflating bag with a valve-mask assembly and a reservoir bag with highflow supplemental oxygen. In some centres a Mapleson C breathing system is used for this purpose (fig 1). The Mapleson C system can also be used for oxygenation during sedation. ${ }^{8}$

Self-inflating bags are universally available in UK emergency departments because they are easy to use and will function without an oxygen supply.
They are appropriate for use during assisted ventilation, but during spontaneous breathing they may increase the resistance to breathing. ${ }^{9}$ Furthermore, a self-inflating bag may deliver a lower inspired oxygen concentration than an anaesthetic breathing system. ${ }^{10}$

We aimed to determine whether a self-inflating bag with reservoir and supplemental oxygen supply provides the same degree of pre-oxygenation as a Mapleson $\mathrm{C}$ anaesthetic breathing system when both are used correctly. We also compared the subjective ease of breathing for patients preoxygenated using these devices.

\section{METHODS \\ Volunteer group}

The volunteer group comprised 20 healthy adults (8 men) recruited from the emergency department at the Bristol Royal Infirmary. None of the volunteers had pre-existing lung disease or organisational involvement in the study. Informed consent was obtained from all participants and the study received approval from the Salisbury and South Wiltshire research ethics committee.

\section{Study design}

Subjects were asked to breathe spontaneously with their normal tidal ventilation through either a Mapleson C breathing system (Vital Signs, New Jersey, USA) with a $60 \mathrm{~cm} \mathrm{H} \mathrm{H}_{2} \mathrm{O}$ adjustable pressure limited valve fully open, or a self-inflating bag and valve (Marshall Products, Bath, UK) attached to a tight fitting anaesthetic mask (size 4 or 5) for $3 \mathrm{~min}$. The self-inflating bag incorporated a valve system to reduce entrainment of air when used for spontaneous ventilation. Subjects were blindfolded so they were not aware of the system from which they were breathing. The mask was held in place by the investigator with firm pressure using standard technique and a good seal maintained at all times, this being monitored by visual positioning of the mask and looking for collapse of the reservoir bag. The investigator had extensive experience of the pre-oxygenation technique. The oxygen flow rate was $15 \mathrm{l} / \mathrm{min}$ from the wall supply to the pre-oxygenation device; although the wall-mounted ball valve flowmeter had not been calibrated before use, the same valve was used for both devices during data collection.

Inspiratory and end expiratory oxygen concentration was recorded every $15 \mathrm{~s}$ using a recently calibrated Datex 254 gas analyser (Datex-Ohmeda, Wisconsin, USA) with a side port gas collection system located at the mask connection. Check readings were taken from the analyser before use in $21 \%$ and $100 \%$ oxygen. 


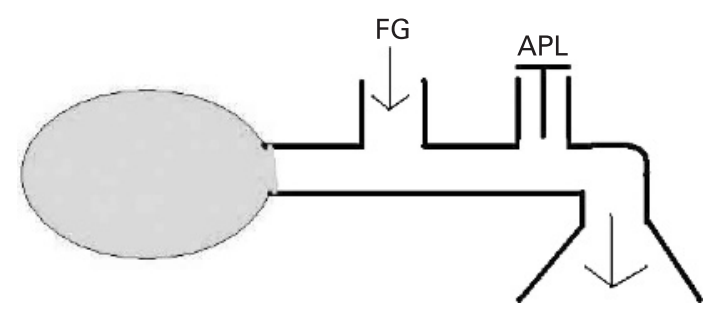

Figure 1 Circuit diagram of Mapleson C system. APL, adjustable pressure limiting valve; FG, fresh gas.

After collecting data for the first device, there was a break of 30 min to allow oxygen washout. The subject then returned to repeat the exercise with the second device.

After each pre-oxygenation the subject was asked to indicate how difficult they felt it was to breathe through the device by placing a mark on a $100 \mathrm{~mm}$ visual analogue scale, with "difficult" marked at $0 \mathrm{~mm}$ and "easy" at $100 \mathrm{~mm}$.

The primary outcome measure was the end expiratory oxygen concentration achieved after breathing through the test system for $3 \mathrm{~min}$. The secondary outcome measure was the subjective ease of breathing indicated by the volunteers using the visual analogue scale.

\section{Data analysis}

Data were recorded on an anonymised results sheet and later entered into an Excel spreadsheet for analysis using a paired Student $t$ test.

The study was powered to detect a clinically significant difference in end expiratory oxygen concentration of $10 \%$ at $3 \min (\alpha=0.05, \beta=0.8)$. Because the data were paired (each subject acted as their own control), a total of 16 volunteers were required $^{11}$ although 20 were recruited.

\section{RESULTS}

The mean end tidal oxygen concentration for the two devices during the $3 \mathrm{~min}$ of pre-oxygenation is shown in fig 2. This demonstrates that, from an identical baseline, the curves immediately diverge and remain separated at $3 \mathrm{~min}$.

The mean (SD) end expiratory oxygen concentration at 3 min was 74.2 (3.8)\% for the self-inflating bag (95\% confidence interval (CI) $72.4 \%$ to $75.9 \%$ ) and 86.2 (3.7)\% for the Mapleson C system (95\% CI $84.5 \%$ to $88.0 \%)(p<0.0001)$. The $95 \%$ CI of the difference between the mean values for end expiratory oxygen concentration at 3 min was $10.0 \%$ to $14.2 \%$.

For the secondary outcome of subjective ease of breathing (where 0 is difficult and 100 is easy), the mean (SD) value for the self-inflating bag was 49.5 (25.0) (95\% CI 37.8 to 61.2) compared with 67.2 (20.3) (95\% CI 57.7 to 76.8) for the Mapleson C system ( $p=0.01)$.

\section{DISCUSSION}

We have shown that the Mapleson C breathing system is superior to the self-inflating bag for pre-oxygenation and also for subjective ease of breathing. The 95\% CI around the difference between the mean values of end expiratory oxygen concentration at 3 min was $10.0 \%$ to $14.2 \%$, which exceeds the prespecified clinically significant difference of $10 \%$. Assuming a functional residual capacity of $2500 \mathrm{ml}$ and oxygen consumption of $250 \mathrm{ml} / \mathrm{min},{ }^{12}$ a $10 \%$ increase in the end expired oxygen concentration would provide an additional minute of apnoea before oxygen desaturation occurs, although oxygen consump-

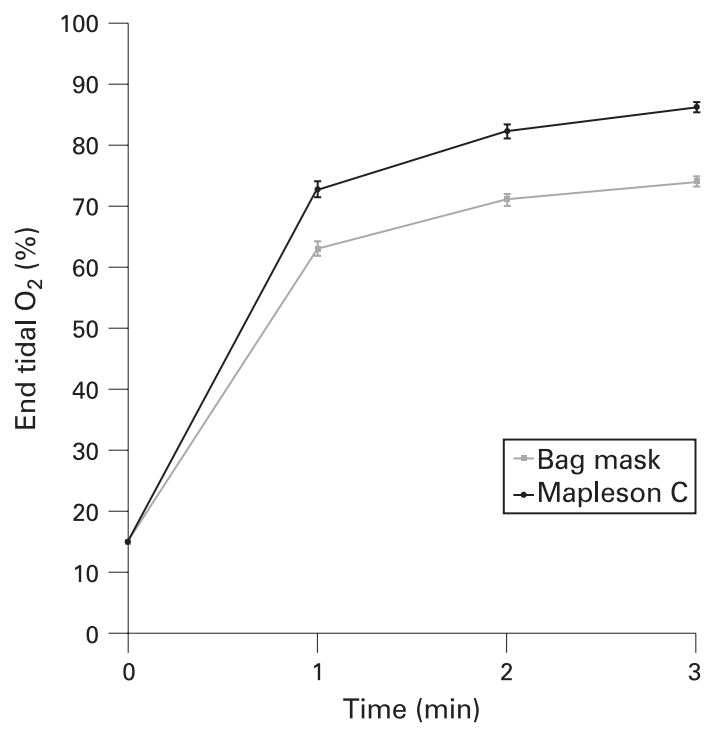

Figure 2 Mean end tidal oxygen concentration during 3 min of preoxygenation (incorporating standard error bars).

tion could be significantly greater than this textbook figure and would therefore reduce this time. This could have important clinical consequences in a difficult intubation.

Our subjects indicated that they found it easier to breathe through the Mapleson C system. This is important because it may further contribute to effective pre-oxygenation. In an emergency environment the patient is often confused, agitated and poorly tolerant of a system that has an appreciable resistance to spontaneous respiration.

There is a possibility that different types of bag valve masks and Mapleson C systems have different properties and our findings may only be applicable to the specific devices we tested. We are aware that, if the minute volume of respiration is increased, this could affect the rate of pre-oxygenation; we did not attempt to measure the minute volume in this study. It is unlikely that the subjects varied their respiration pattern enough to account for the overall differences we observed between the breathing systems. This study was not double blind; although we made an attempt to blind the subjects, we could not think of a method of double blinding so we cannot rule out unintentional observer bias.

Experienced airway practitioners may prefer to use a Mapleson C system for pre-oxygenation because it gives a better impression of lung and chest wall compliance and tidal volume. However, there are important pitfalls in the use of a Mapleson C breathing system. Inexperienced operators may be tempted to counter bag collapse by screwing down the adjustable pressure limiting (APL) valve (rather than increasing the oxygen flow), which can lead to re-breathing and hypercapnia. Also, the Mapleson $\mathrm{C}$ will not function if the gas supply fails; for this reason, self-inflating bags must always accompany a patient during transfer. Practitioners lacking formal anaesthetic training are unlikely to be skilled in the use of a Mapleson C breathing system, and the routine placement of these devices in emergency departments could lead to misuse.

In conclusion, we have shown that the Mapleson $\mathrm{C}$ breathing system is superior to the self-inflating bag for emergency preoxygenation before rapid sequence induction of anaesthesia. However, there are several disadvantages associated with the Mapleson $\mathrm{C}$ breathing system and any decision to adopt it as a 
standard pre-oxygenation device in the emergency department must take these into consideration.

Acknowledgements: The authors thank the staff of the Bristol Royal Infirmary emergency department who volunteered to take part in this study.

Funding: This research was supported by charitable grants from the Mason Medical Research Foundation and the UK College of Emergency Medicine.

Competing interests: None.

\section{REFERENCES}

1. Gold MI. Pre-oxygenation. Br J Anaesth 1989;62:241-2.

2. Bair AE, Filbin MR, Kulkarni RG, et al. The failed intubation attempt in the emergency department: analysis and prevalence, rescue techniques and personnel. J Emerg Med 2002;23:131-40.

3. Graham CA, Beard D, Oglesby AJ, et al. Rapid sequence intubation in Scottish urban emergency departments. Emerg Med J 2003;20:3-5.
4. Stafford R, Benger J, Nolan J. Preoxygenation remains essential before emergency tracheal intubation. Crit Care Med 2006;34:1859-60.

5. Simpson J. Rapid sequence intubation in the emergency department: 5 year trends. Emerg Med J 2006:23:54-6.

6. Winship S, Skinner A. Vital Capacity and tidal volume preoxygenation with a mouthpiece. Br J Anaesth 1998;81:787-9.

7. Hirsch J, Fuhrer I, Kuhly P, et al. Pre-oxygenation: a comparison of three different breathing systems. Br J Anaesth 2001;87:928-31.

8. Dunn MJG. Evaluation of propofol and remifentanil for intravenous sedation for reducing shoulder dislocations in the emergency department. Emerg Med J 2006;23:57-8.

9. International Organisation for Standardisation. Lung ventilators part 4: particular requirements for operator powered resuscitators. International Standard 10651-4. Geneva: International Organisation for Standardisation, 2002.

10. Mills PJ, Baptiste J, Preston J, et al. Manual resuscitators and spontaneous ventilation - an evaluation. Crit Care Med 1991:19:1425-31.

11. Campbell MJ, Julious SA, Altman DG. Estimating sample sizes for binary, ordered categorical and continuous outcomes in two group comparisons. BMJ 1995:311:1145-8.

12. Ganong WF. Review of medical physiology. 21st edn. USA: Large Medical Books/ McGraw-Hill, 2003.

\section{Images in emergency medicine}

\section{A rare cause of acute urinary retention}

A 59-year-old man presented with back pain, and inability to pass urine. Physical examination showed a blood pressure of $147 / 90 \mathrm{~mm} \mathrm{Hg}$, a pulse rate of 110 beats/min, mild oedema of both legs, and generalised tenderness in the suprapubic region. Laboratory investigations confirmed: a red cell count of $2.20 \times 10^{9} / 1$; haemoglobin $68 \mathrm{~g} / 1$; creatinine $900 \mu \mathrm{mol} / \mathrm{l}$; C reactive protein $109 \mathrm{mg} / \mathrm{l}$ (normal $<5 \mathrm{mg} / \mathrm{l}$ ).

Ultrasonography showed a distended urinary bladder. A urethral catheter was inserted, and it occluded after drainage of $500 \mathrm{ml}$ of blood-stained urine. A computed tomography scan demonstrated an inhomogeneous mass in the overdistended urinary bladder, large parapelvinic cysts and bilaterally dilated ureters (fig 1). The mass within the bladder was removed endoscopically. Histopathological examination confirmed a large blood coagulum without malignancy. A postoperative endoscopy disclosed multiple venous varices on the base of the bladder. The patient's postprocedural period was uneventful.

\footnotetext{
A Surov, ${ }^{1}$ M Katzer, ${ }^{2}$ P Fornara, ${ }^{2}$ K Stock ${ }^{1}$

${ }^{1}$ Department of Radiology, Martin-Luther-University Halle, Wittenberg, Germany;

${ }^{2}$ Department of Urology, Martin-Luther-University Halle, Wittenberg, Germany
}

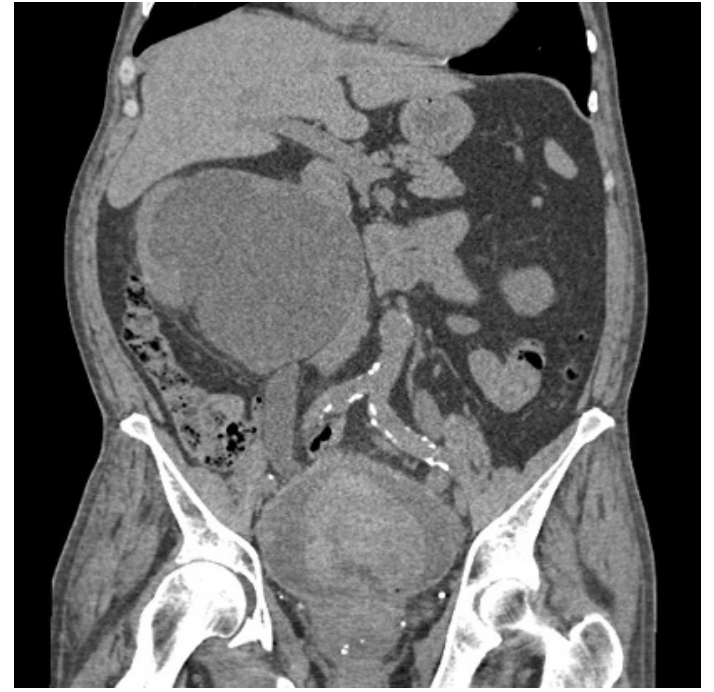

Figure 1 Computed tomography scan of the bladder.

Correspondence to: Dr A Surov, Ernst-Grubestr 40, Halle, 06097 Germany; alex.surow@medizin.uni-halle.de

Emerg Med J 2008;25:155. doi:10.1136/emj.2007.048900 


\section{Self-inflating bag or Mapleson $\mathrm{C}$ breathing system for emergency pre-oxygenation?}

R A Stafford, J R Benger and J Nolan

Emerg Med J 2008 25: 153-155

doi: 10.1136/emj.2007.050708

Updated information and services can be found at:

http://emj.bmj.com/content/25/3/153.full.html

\section{These include:}

References This article cites 10 articles, 6 of which can be accessed free at: http://emj.bmj.com/content/25/3/153.full.html\#ref-list-1

Email alerting Receive free email alerts when new articles cite this article. Sign up in service the box at the top right corner of the online article.

Notes

To request permissions go to:

http://group.bmj.com/group/rights-licensing/permissions

To order reprints go to:

http://journals.bmj.com/cgi/reprintform

To subscribe to BMJ go to:

http://group.bmj.com/subscribe/ 